\title{
Comparison of Atrial-His Intervals During Tachycardia and Atrial Pacing in Patients with Long RP Tachycardia
}

\author{
K. CHING MAN, D.O., MARK NIEBAUER, M.D., EMILE DAOUD, M.D., \\ S. ADAM STRICKBERGER, M.D., WILLIAM KOU, M.D., \\ BRIAN D. WILLIAMSON, M.D., and FRED MORADY, M.D. \\ From the Department of Internal Medicine, Division of Cardiology, \\ University of Michigan Medical Center, Ann Arbor, Michigan
}

Long RP Tachycardia. Introduction: The purpose of this study is to describe a simple and reliable diagnostic maneuver that allows for the rapid differentiation of atypical AV nodal reentrant tachycardia (AVNRT) from other causes of long RP tachycardia. Long RP tachycardias may be caused by atypical AVNRT, orthodromic reciprocating tachycardia (ORT) involving a slowly conducting retrograde accessory pathway, or atrial tachycardia. The differentiation of atypical AVNRT from ORT or atrial tachycardia may be difficult, especially when the differential diagnosis includes a posteroseptal accessory pathway or an atrial tachycardia arising in the posteroseptal right atrium.

Methods and Results: Twelve patients with atypical AVNRT, 21 with ORT, and 12 with an atrial tachycardia diagnosed using conventional criteria were enrolled in this study. The atrialHis $(\mathrm{AH})$ interval was measured at the His-bundle position during the tachycardia and during atrial pacing from the high right atrium at the tachycardia cycle length in the setting of sinus rhythm. In patients with atypical AVNRT, the mean AH interval was $69 \mathrm{msec} \pm \mathbf{5 0}$ msec ( \pm SD) longer during high right atrial pacing than during the tachycardia $(\mathrm{P}<0.001)$. In 10 of 12 patients with atypical AVNRT, the AH interval during atrial pacing was more than $\mathbf{4 0} \mathbf{m s e c}$ longer than the AH interval measured during the tachycardia. In contrast, in patients with ORT or atrial tachycardia, the differences in AH interval between atrial pacing and tachycardia were never more than 20 and $10 \mathrm{msec}$, respectively.

Conclusion: The difference in the AH interval between atrial pacing and the tachycardia allows a simple and rapid means of differentiating atypical AVNRT from other types of long RP tachycardias. (J Cardiovasc Electrophysiol, Vol. 6, pp. 700-710, September 1995)

long RP tachycardia, atrial pacing, atrial-His interval

\section{Introduction}

The three possible mechanisms of long RP tachycardia consist of atypical (fast-slow) AV nodal reentrant tachycardia (AVNRT), orthodromic reciprocating tachycardia utilizing a relatively slowly conducting accessory pathway in the retrograde direction, and atrial tachycardia. ${ }^{1.2}$ Using standard

Address for correspondence: Fred Morady, M.D., University of Michigan Medical Center, 1500 East Medical Center Dr., B1F245Ann Arbor, MI 48109-0022. Fax: 313-936-7026 [, 45\$)

Manuscript received 29 March 1995; Accepted for publication 10 July 1995 . diagnostic criteria, atypical AVNRT usually can be distinguished from the other two mechanisms of long RP tachycardia without difficulty. ${ }^{1,-6}$ However, at times the differentiation of atypical AVNRT from orthodromic tachycardia utilizing a slowly conducting accessory pathway or an atrial tachycardia may be challenging, particularly when the differential diagnosis includes a posteroseptal accessory pathway or an atrial tachycardia arising in the posteroseptal right atrium. ${ }^{6}$ The purpose of this study is to describe a simple and reliable diagnostic maneuver that allows for the rapid differentiation of atypical AVNRT from other types of long RP tachycardia. 
TABLE 1

Characteristics of Long RP Tachycardias

\begin{tabular}{cccc}
\hline & $\begin{array}{c}\text { Atypical } \\
\text { AVNRT }\end{array}$ & $\begin{array}{c}\text { Orthodromic } \\
\text { Tachycardia }\end{array}$ & $\begin{array}{c}\text { Atrial } \\
\text { Tachycardia }\end{array}$ \\
\hline $\begin{array}{c}\text { Number of } \\
\text { patients } \\
\begin{array}{c}\text { Cycle length } \\
\text { (msec) }\end{array}\end{array}$ & 12 & 21 & 12 \\
$\begin{array}{c}\text { PR interval } \\
\text { (msec) }\end{array}$ & $149 \pm 68$ & $326 \pm 48$ & $337 \pm 31$ \\
$\begin{array}{c}\text { RP interval } \\
\text { (msec) }\end{array}$ & $204 \pm 45$ & $191 \pm 42$ & $218 \pm 28$ \\
\hline
\end{tabular}

Measurements are expressed as mean \pm SD.

$* \mathrm{P}<0.05$ vs atypical AVNRT. There were no other significant differences in measurements among the three groups.

AVNRT $=$ atrioventricular nodal reentrant tachycardia.

\section{Methods}

\section{Patient Characteristics}

The subjects of this study were 45 patients with a long RP tachycardia induced during an electrophysiologic test. Long RP tachycardia was defined as a narrow QRS tachycardia in which the RP interval was longer than the PR interval in any of the 12 ECG leads. Patients with overt preexcitation were excluded, as were patients in whom the tachycardia cycle length varied by more than $10 \mathrm{msec}$ and five patients in whom there was not 1:1 AV conduction during atrial pacing at the tachycardia cycle length in the setting of sinus rhythm. There were 25 women and 20 men (mean age $44 \pm 19$ years [ \pm SD]). None of the patients had structural heart disease. The mean long RP tachycardia cycle length was $332 \pm 49 \mathrm{msec}$. During tachycardia, the mean PR interval was $133 \pm 29 \mathrm{msec}$ and the mean RP interval was $201 \pm 40 \mathrm{msec}$. Twelve patients had atypical AVNRT, 21 patients had orthodromic tachycardia, and 12 patients had an atrial tachycardia (Table 1). Seven of the accessory pathways and two of the atrial tachycardias were posteroseptal in location.

\section{Electrophysiologic Testing}

Electrophysiologic tests were performed after informed consent was obtained and after discontinuation of all antiarrhythmic agents for at least 5 half-lives. Three quadrapolar electrode catheters with 2- to 5-mm interelectrode spacing were inserted into a femoral vein and positioned in the high right atrium, His-bundle position, and right ventricular apex. Whenever necessary, one of these catheters was manipulated into the coronary sinus. Several ECG leads and the intracardiac electrograms were displayed on an oscilloscope and recorded at a paper speed of $100 \mathrm{~mm} / \mathrm{sec}$ on a Mingograph 7 recorder (Siemens-Elema, Solna, Sweden) or BARD Lab system 64 (Tewksbury, MA, USA). Pacing was performed with a programmable stimulator (Bloom Associates, Reading PA, USA) using stimuli at twice diastolic threshold and $2 \mathrm{msec}$ in duration.

The conduction properties and refractory periods of the AV node were assessed. Dual AV nodal physiology was defined as a 50 -msec or more increment in the $\mathrm{A}_{2} \mathrm{H}_{2}$ interval in association with a 10-msec decrement in the $A_{1} A_{2}$ interval. Paroxysmal supraventricular tachycardia was induced by rapid atrial pacing, ventricular pacing, or programmed atrial stimulation. The mechanism of supraventricular tachycardia was determined using standard criteria, which have been previously described. ${ }^{1,3,4,6}$ The criteria used to diagnose orthodromic reciprocating tachycardia were: the ability to preexcite or delay the atrial electrograms during tachycardia with a ventricular premature depolarization coincident with His-bundle refractoriness; an increase in the ventriculoatrial (VA) interval during ipsilateral bundle branch block; and the ability to terminate the tachycardia with a ventricular premature depolarization coincident with the His-bundle depolarization. The criteria used to diagnose an atrial tachycardia were: the inability to terminate the tachycardia by ventricular pacing without depolarization of the atria; a variable AV or VA relationship in the first postpacing beat after entrainment of the tachycardia

TABLE 2

AH Intervals During Tachycardia and During Right Atrial Pacing at the Tachycardia Cycle Length

\begin{tabular}{lcccc}
\hline & AH During Tachycardia & AH During Pacing & $\Delta$ AH & P Value \\
\hline Atypical AVNRT & $101 \pm 32$ & $170 \pm 63$ & $69 \pm 50$ & $<0.001$ \\
Orthodromic tachycardia & $129 \pm 39$ & $130 \pm 63$ & $1 \pm 8$ & NS \\
Atrial tachycardia & $110 \pm 16$ & $110 \pm 20$ & $0 \pm 8$ & NS \\
\hline
\end{tabular}

Measurements (in $\mathrm{msec}$ ) are expressed as mean \pm SD. 
by atrial or ventricular pacing; and a different atrial activation sequence during tachycardia and during ventricular pacing in the setting of sinus rhythm. Atypical AVNRT was diagnosed using the following criteria: earliest retrograde atrial activation near the ostium of the coronary sinus during tachycardia; reproduction of the same atrial activation sequence during ventricular pacing as during tachycardia; continuation of tachycardia during AV block (four patients); the inability to preexcite the atria during tachycardia with a ventricular depolarization introduced during His-bundle refractoriness either at the right ventricular apex (six patients) or near the summit of the right ventricular septum (six patients) ${ }^{7}$; fixed AV or VA relationship in the first postpacing beat after entrainment of the tachycardia by a trial or ventricular pacing; and exclusion of orthodromic reciprocating and atrial tachycardia.

\section{Study Protocol and Data Analysis}

In every patient, the high right atrium was paced in the setting of sinus rhythm at a cycle length

\section{Atypical AVNRT, CL $350 \mathrm{msec}$}

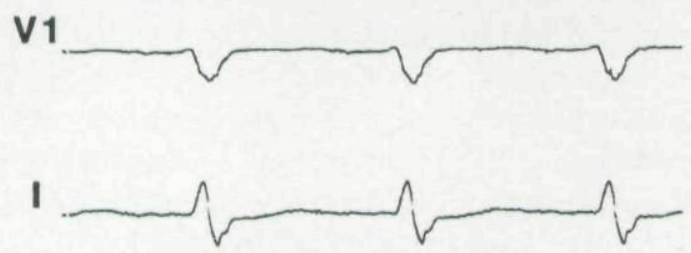

II
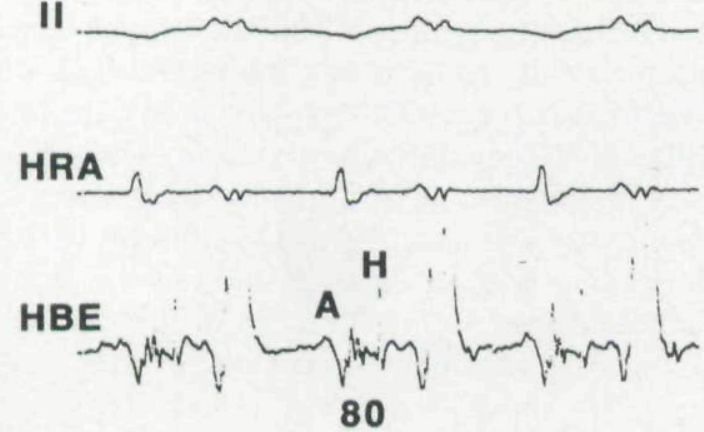

equal to the cycle length of the long RP tachycardia. In addition, during tachycardia, atrial pacing was performed at cycle lengths 10 to 20 msec shorter than the tachycardia cycle length in an attempt to entrain the tachycardia.

Measurements of the atrial-His ( $\mathrm{AH})$ interval were performed manually to the nearest $5 \mathrm{msec}$ in blinded fashion from recordings obtained at a paper speed of $100 \mathrm{~mm} / \mathrm{sec}$. The AH interval was measured from the onset of the first rapid deflection of the atrial electrogram recorded by the Hisbundle catheter to the onset of the first rapid deflection of the His-bundle potential. A rapid deflection was defined as a deflection that had a slope of at least $45^{\circ}$ at a recording speed of 100 $\mathrm{mm} / \mathrm{sec}^{8}{ }^{8}$ The intraobserver reproducibility of the $\mathrm{AH}$ interval measurements was $93 \%$, and the interobserver reproducibility was $88 \%$. Differences in measurements were resolved by a third observer.

The $\triangle \mathrm{AH}$ was defined as the difference between the $\mathrm{AH}$ interval measured during atrial pacing at the tachycardia cycle length in the setting of sinus rhythm and the $\mathrm{AH}$ interval measured during the long RP tachycardia.

\section{RA Pacing, CL 350 msec}
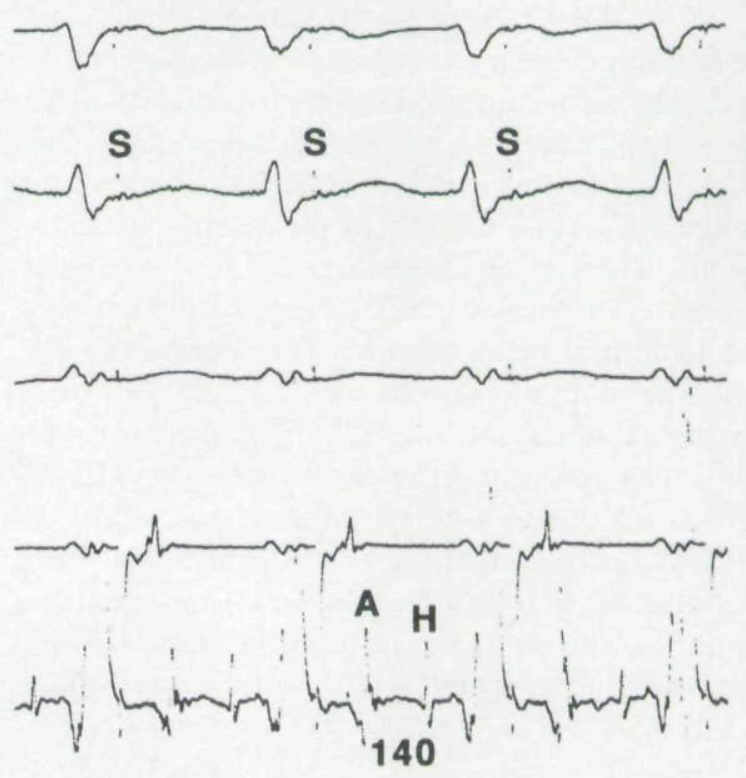

$500 \mathrm{msec}$

Figure 1. A comparison of AH intervals during atypical AV nodal reentrant tachycardia (AVNRT) and high right atrial (RA) pacing. The left panel demonstrates atypical AVNRT at a cycle length $(C L)$ of $350 \mathrm{msec}$. The AH interval during the tachycardia is $80 \mathrm{msec}$. The right panel demonstrates pacing from the high right atrium at the tachycardia cycle length in the setting of sinus rhythm, with a resultant $A H$ interval of $140 \mathrm{msec}$. The $\triangle A H$ is $60 \mathrm{msec} . A H=$ atrial-His interval; HRA $=$ high right atrium; $H B E=$ His-bundle electrogram; $S=$ stimulus artifact. 


\section{Statistical Analysis}

Values are expressed as mean $\pm \mathrm{SD}$. Continuous variables were compared using either the Student's paired $t$-test or by ANOVA. A P value $<$ 0.05 was considered significant.

\section{Results}

\section{The AH Interval in Response to Atrial Pacing}

(Table 2)

In the patients who had atypical AVNRT, the mean $\mathrm{AH}$ intervals during pacing and tachycardia were $170 \pm 63 \mathrm{msec}$ and $101 \pm 32 \mathrm{msec}(P$ $<0.001$ ), yielding a mean $\Delta \mathrm{AH}$ of $69 \pm 50 \mathrm{msec}$ (Fig. 1). In contrast, in the patients with orthodromic reciprocating tachycardia, the $\mathrm{AH}$ intervals during pacing and tachycardia did not differ significantly and the mean $\triangle \mathrm{AH}$ was $1 \pm 8$ msec (Fig. 2). Similarly, in the patients who had an atrial tachycardia, the $\mathrm{AH}$ intervals during pacing and tachycardia did not differ significantly, and the mean $\triangle \mathrm{AH}$ was $0 \pm 8 \mathrm{msec}$ (Fig. 3). Four of the patients with orthodromic reciprocating tachycardia and two of the patients with an atrial tachycardia had dual AV nodal physiology.

In 10 of 12 patients with atypical AVNRT, the $\triangle \mathrm{AH}$ was $40 \mathrm{msec}$ or more and in two patients, it was $10 \mathrm{msec}$ or less. In all patients with orthodromic $\mathrm{AV}$ reentrant tachycardias, the $\triangle \mathrm{AH}$ never exceeded $20 \mathrm{msec}$. In all patients who had an atrial tachycardia, the $\triangle \mathrm{AH}$ never exceeded $10 \mathrm{msec}$ (Fig. 4).

\section{Induction of Atypical AVNRT with Atrial and Ventricular Pacing}

In the 10 patients with atypical AVNRT in whom there was a $\triangle \mathrm{AH}$ of $40 \mathrm{msec}$ or more, atrial pacing at the same cycle length as the tachycardia never induced atypical AVNRT (Fig. 5). In contrast, in the two patients in whom the $\triangle \mathrm{AH}$ was $10 \mathrm{msec}$ or less, atypical AVNRT was consistently induced by atrial pacing at the tachycardia cycle length (Fig. 6).

In the 10 patients with atypical AVNRT in whom the $\triangle \mathrm{AH}$ was $40 \mathrm{msec}$ or more, the mean effec-

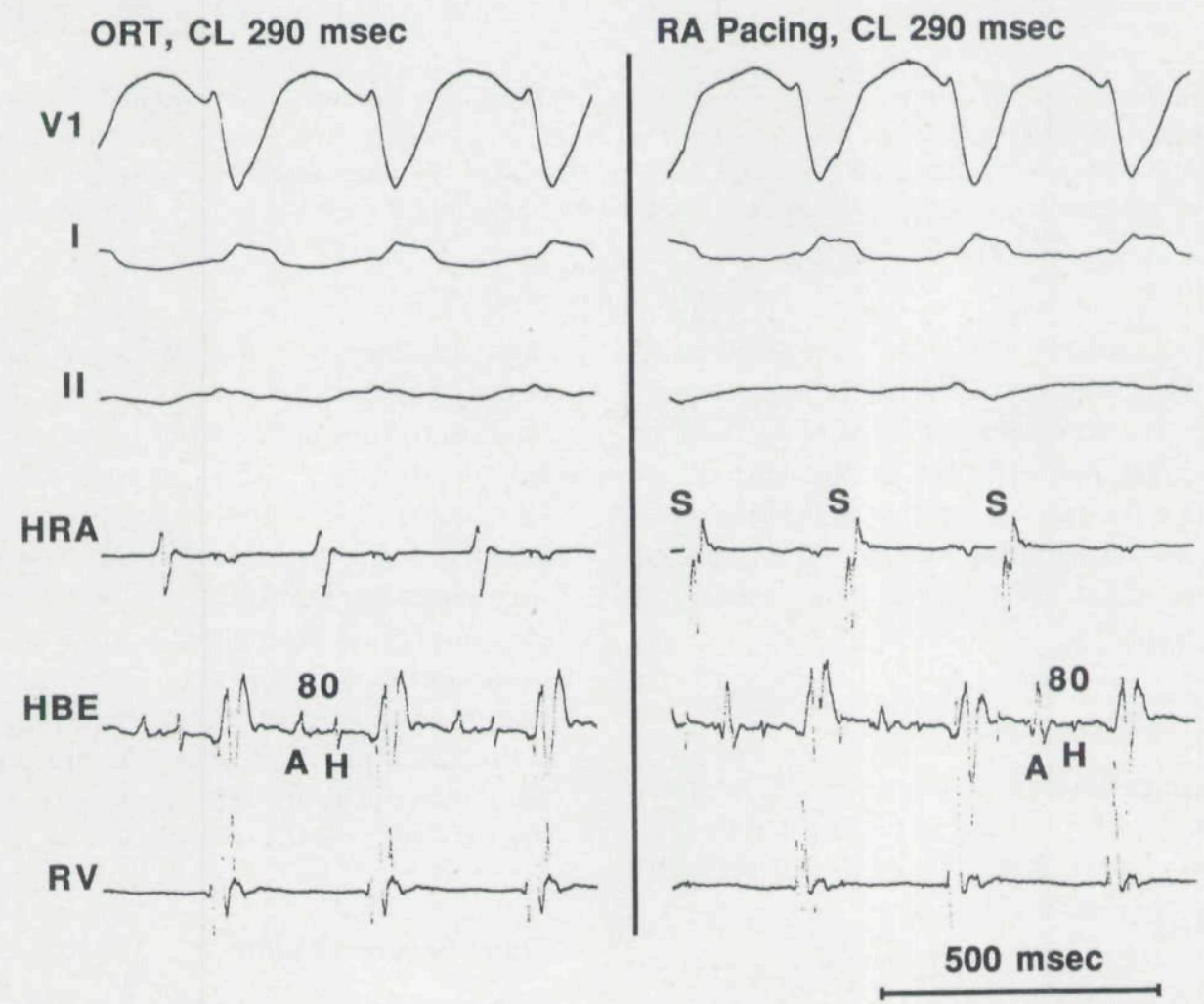

Figure 2. A comparison of AH intervals during orthodromic reciprocating tachycardia (ORT) and high right atrial (RA) pacing. The left panel demonstrates ORT at a cycle length (CL) of $290 \mathrm{msec}$. The AH interval during the tachycardia is $80 \mathrm{msec}$. The right panel demonstrates pacing from the high right atrium at the tachycardia cycle length in the setting of sinus rhythm, with a resultant $A H$ interval also of $80 \mathrm{msec}$. Therefore, the $\triangle A H$ in this case is $0 . R V=$ right ventricle; other abbreviations as in Figure 1. 


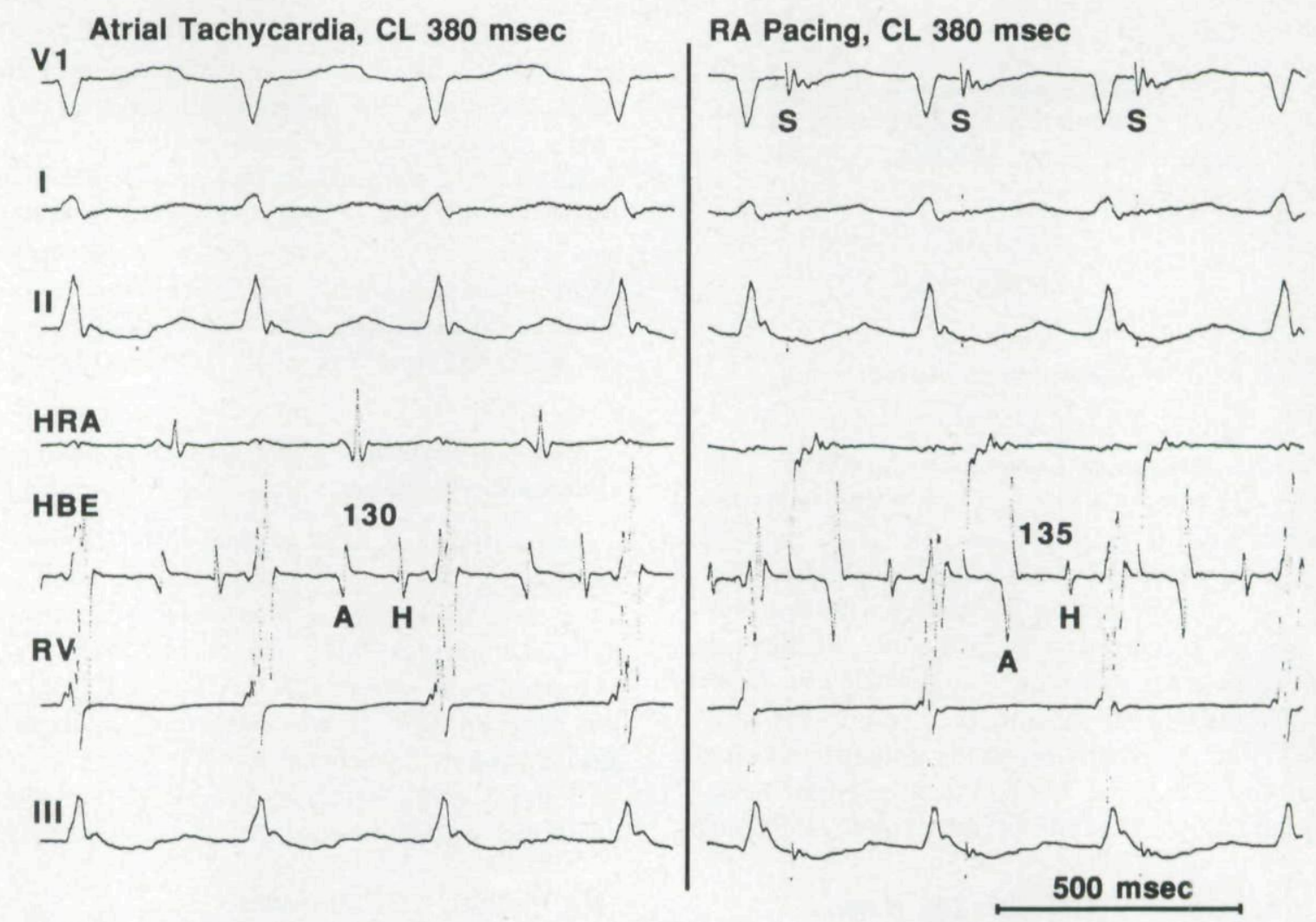

Figure 3. A comparison of AH intervals during atrial tachycardia and high right atrial (RA) pacing. The left panel demonstrates an example of atrial tachycardia at a cycle length $(C L)$ of $380 \mathrm{msec}$. The AH interval during the tachycardia is 130 msec. The right panel demonstrates pacing from the high right atrium at the tachycardia cycle length in the setting of sinus rhythm, with a resultant AH interval of $135 \mathrm{msec}$. Therefore, the $\triangle A H$ in this case is $5 \mathrm{msec}$. Abbreviations as in previous figures.

tive refractory periods of the fast and slow pathways were $313 \pm 86$ and $276 \pm 83 \mathrm{msec}$, respectively. In the two patients with atypical AVNRT in whom the $\triangle \mathrm{AH}$ was $10 \mathrm{msec}$ or less, the effective refractory periods of the fast and slow pathways could not be accurately measured because of repeated induction of tachycardia during the basic drive trains.

\section{The AH Interval During Entrainment}

During entrainment of atypical AVNRT by pacing at the high right atrium, the $\mathrm{AH}$ interval prolonged by 10 to $20 \mathrm{msec}$ compared to the $\mathrm{AH}$ interval during tachycardia (Fig. 7).

\section{Discussion}

\section{Main Findings}

The results of this study demonstrate that the $\mathrm{AH}$ interval during atrial pacing at the tachycar- dia cycle length in the setting of sinus rhythm is usually at least $40 \mathrm{msec}$ longer than the $\mathrm{AH}$ interval during tachycardia in patients with atypical AVNRT. In contrast, in patients with an atrial tachycardia or orthodromic reciprocating tachycardia utilizing a relatively slowly conducting accessory pathway, the difference in AH intervals during pacing and during tachycardia is usually $<10$ msec and never more than $20 \mathrm{msec}$. Therefore, a comparison of $\mathrm{AH}$ intervals during pacing and tachycardia provides a simple and quick diagnostic maneuver to distinguish atypical AVNRT from the two other types of long RP tachycardia.

\section{Upper Common Pathway}

A possible explanation for a difference in $\mathrm{AH}$ intervals during pacing and tachycardia in patients with atypical AVNRT is the presence of an upper common pathway in the reentrant circuit that generates this tachycardia. Because an upper common pathway would be used in the retrograde direction 


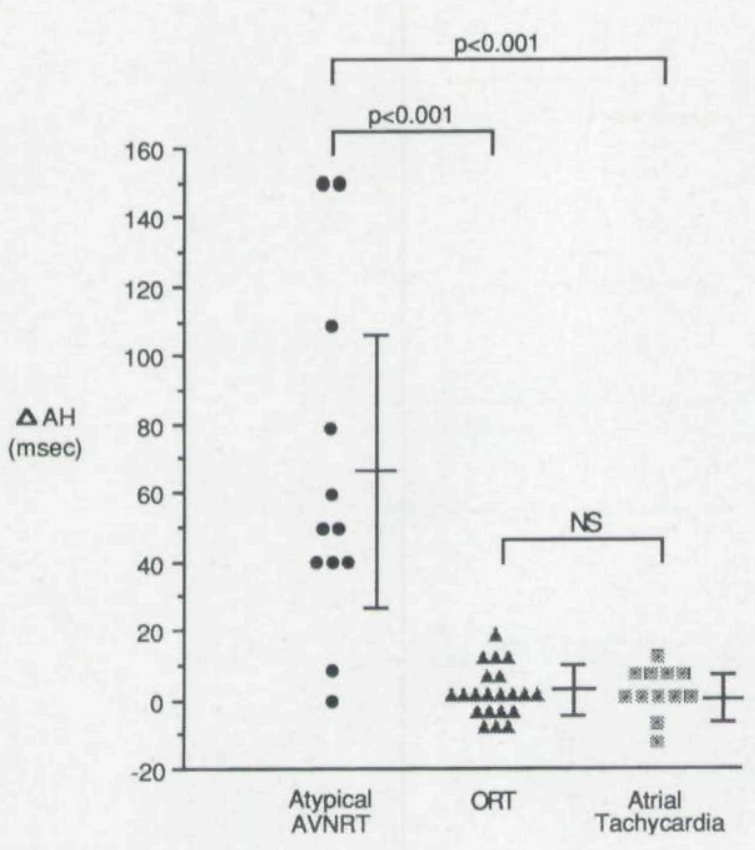

Figure 4. A comparison of the $\triangle A H$ in patients with atypical AV nodal reentrant tachycardia (AVNRT), orthodromic tachycardia (ORT), and atrial tachycardia. The $\triangle A H$ represents the difference between the $A H$ interval during atrial pacing in the setting of sinus rhythm at the tachycardia cycle length and the $A H$ interval during the tachycardia. All AH intervals were measured from the His-bundle electrogram. The vertical bars represent the mean $\pm 1 S D$. AH $=$ atrial-His interval; $N S=$ not significant .

during tachycardia and in the anterograde direction during atrial pacing, the $\mathrm{AH}$ interval during pacing at the tachycardia cycle length in the setting of sinus rhythm would be expected to be longer than during a tachycardia (Fig. 8). ${ }^{9}$

In two patients with typical (slow-fast) AVNRT, Miller et al. ${ }^{9}$ found that the $\mathrm{AH}$ interval during pacing was longer than during tachycardia, although only by 5 to $9 \mathrm{msec}$. This observation was used as evidence for the presence of an upper common pathway in the reentrant circuit of AVNRT. Assuming that anterograde and retrograde conduction velocity in an upper common pathway are similar, the mean $\triangle \mathrm{AH}$ of approximately $60 \mathrm{msec}$ in the patients in this study who had atypical AVNRT would indicate a mean upper common pathway conduction interval of approximately 30 msec at the tachycardia cycle length.

Although the possibility of an upper common pathway cannot be definitively excluded, the response to entrainment in patients with atypical AVNRT suggests that this possibility is unlikely. If there were an upper common pathway, conduction over the upper common pathway and the anterograde fast pathway would have to occur sequentially during entrainment by high right atrial pacing, as opposed to simultaneously during the uninterrupted tachycardia. Therefore, the $\mathrm{AH}$ interval during entrainment would be expected to exceed the $\mathrm{AH}$ interval during tachycardia by at least as much as the difference in $\mathrm{AH}$ intervals between pacing in the setting of sinus rhythm and tachycardia (Fig. 8). However, during entrainment of atypical AVNRT in the patients in this study, the AH interval lengthened by only 10 to $20 \mathrm{msec}$, which is readily explained simply by decremental conduction during pacing at a cycle length slightly shorter than the tachycardia cycle length. The fact that the $\triangle \mathrm{AH}$ during entrainment was only 10 to $20 \mathrm{msec}$, as compared to approximately $70 \mathrm{msec}$ when pacing in the setting of sinus rhythm, provides strong evidence against the presence of an upper common pathway in the reentrant circuit of atypical AVNRT. This finding is in concert with the results of prior studies, which have provided other lines of evidence that an upper common pathway does not exist in the reentrant circuit of AVNRT. ${ }^{10-15}$

\section{Induction of Atypical AVNRT by Atrial Pacing}

In every patient with atypical AVNRT in whom there was a $\triangle \mathrm{AH}>40 \mathrm{msec}$, atrial pacing at the tachycardia cycle length in the setting of sinus rhythm never resulted in the induction of tachycardia. In contrast, in the two patients in whom a $\triangle \mathrm{AH}$ exceeding $40 \mathrm{msec}$ was not demonstrated during atrial pacing, atrial pacing consistently resulted in the induction of the atypical AVNRT. The strong association between the absence of a $\triangle \mathrm{AH}$ and the induction of atypical AVNRT suggests that the $\triangle \mathrm{AH}$ in patients with atypical AVNRT is attributable to anterograde conduction over the fast pathway during tachycardia and over the slow pathway during atrial pacing.

Because the effective refractory period of the fast pathway is usually longer than that of the slow pathway, atrial pacing at the tachycardia cycle length might often result in anterograde block in the fast pathway and anterograde conduction over the slow pathway, which would not be expected to induce the fast-slow form of AVNRT. In contrast, if atrial pacing induces atypical AVNRT, anterograde conduction during pacing would, by necessity, have had to occur over the fast pathway, explaining the similarity in $\mathrm{AH}$ intervals during pacing and tachycardia. 


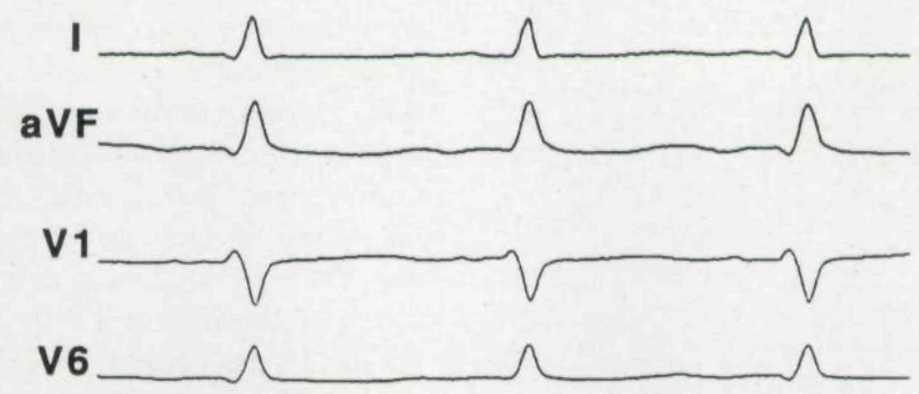

\section{HRA}
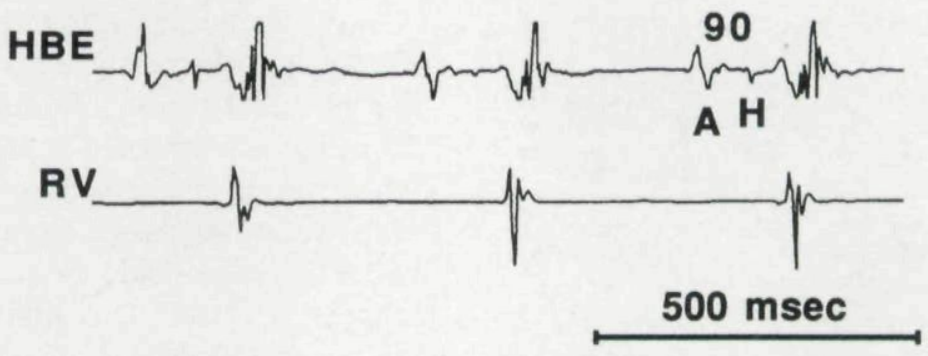

A

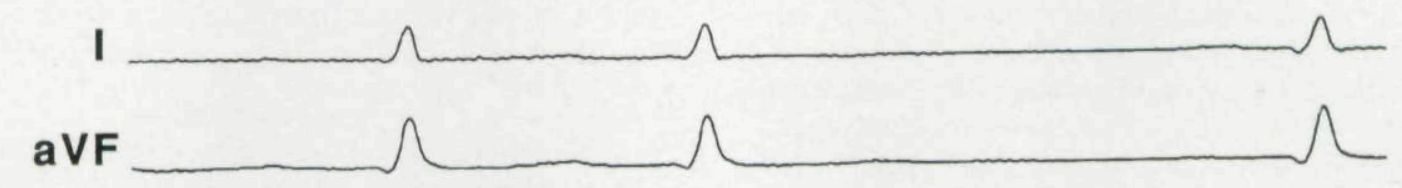

\section{V1}

V6
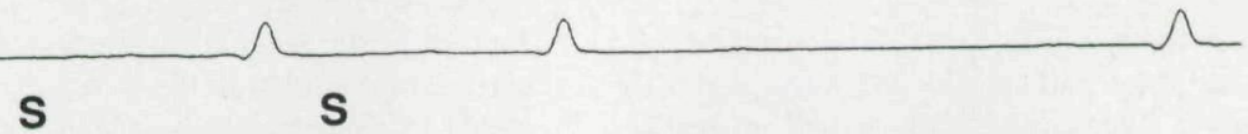

HRA $\rightarrow$ A

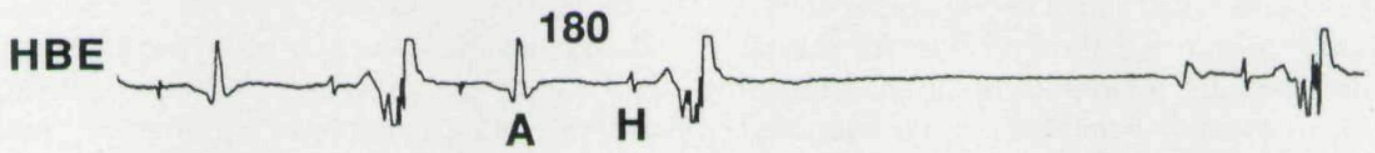

RV

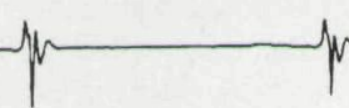

B

\section{$500 \mathrm{msec}$}

Figure 5. An example of a patient with atypical AV nodal reentrant tachycardia (AVNRT) in whom there was a $\triangle A H$ of 90 msec and the failure to induce atypical AVNRT with atrial pacing. (A) Atypical AVNRT with a cycle length of 450 msec and an AH interval of $90 \mathrm{msec}$. (B) High right atrial pacing at the tachycardia cycle length of 450 msec in the setting of sinus rhythm with a resultant $A H$ of $180 \mathrm{msec}$. Note that the tachycardia was not induced by the atrial pacing that demonstrated the $\triangle A H$ of $90 \mathrm{msec}$. Abbreviations as in previous figures. 


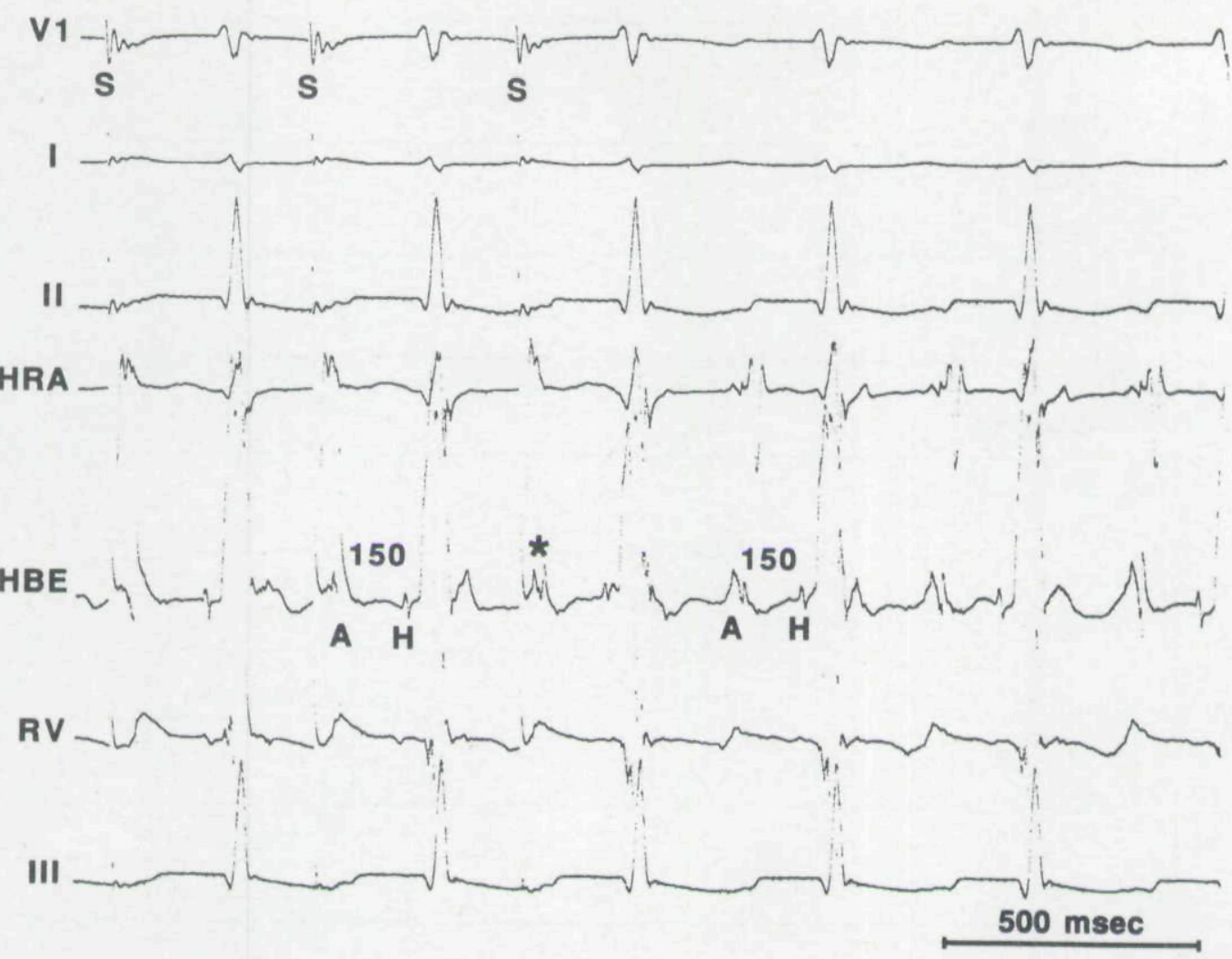

Figure 6. An example of a patient with atypical AV nodal reentrant tachycardia (AVNRT) with a cycle length of $410 \mathrm{msec}$ in whom there was a $\triangle A H$ of $O$ and the induction of atypical AVNRT by atrial pacing at a cycle length of $410 \mathrm{msec}$. The AH intervals during atypical AVNRT and high right atrial pacing were $150 \mathrm{msec}$. The last three stimuli $(S)$ of an atrial pacing train at a cycle length of 410 msec are shown, and the tachycardia was induced (asterisk) by the next to last pacing stimulus. Abbreviations as in previous figures.

\section{Effects of Sympathetic Tone}

Sympathetic activation during tachycardia might explain the presence of a shorter $\mathrm{AH}$ interval during the tachycardia than during atrial pacing at the same cycle length as the tachycardia in the setting of sinus rhythm. However, the mean tachycardia cycle lengths in the patients in this study who had atypical AVNRT, orthodromic reciprocating tachycardia, and atrial tachycardia were similar, and, therefore, any effects caused by adrenergic activation should be similar in magnitude among the three types of tachycardia. Although an increase in sympathetic tone during tachycardia might explain the small $\triangle \mathrm{AH}$ observed in some of the patients who had orthodromic reciprocating tachycardia or atrial tachycardia, this is an unlikely explanation for the mean $\triangle \mathrm{AH}$ of approximately $70 \mathrm{msec}$ in the patients who had atypical AVNRT.

\section{Electrotonus}

An electrotonic interaction between the fast and slow pathways has been postulated to occur in patients with AVNRT. ${ }^{16}$ Electrotonic inhibition of the fast pathway by the slow pathway during atrial pacing but not during tachycardia may provide another possible explanation for the $\Delta \mathrm{AH}$ in patients with atypical AVNRT. If the slow pathway were to exert an electrotonic effect on the fast pathway only when it is depolarized in the anterograde direction, and if atrial pacing at the tachycardia cycle length resulted in anterograde conduction through the fast pathway and anterograde penetration of the slow pathway, this could explain the occurrence of a shorter $\mathrm{AH}$ interval during tachycardia than during atrial pacing. The association between the absence of a $\triangle \mathrm{AH}$ and the induction of atypical AVNRT could also be explained by this mechanism, because simultaneous penetration of the fast and slow pathways during atrial pacing would not be expected to induce tachycardia, while selective anterograde conduction in the fast pathway during atrial pacing could explain both an absence of electrotonic inhibition of the fast pathway and the induction of tachycardia. 
V1

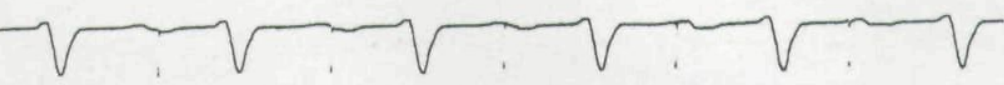

HRA

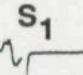

$\mathrm{S}_{2}$
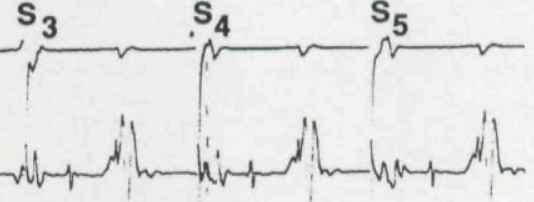

HBE
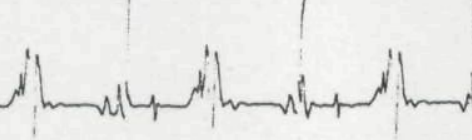

Prox CS

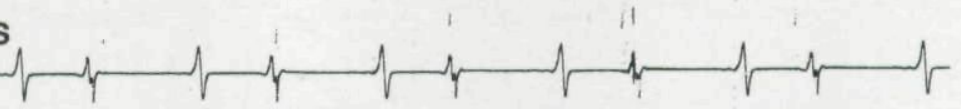

Distal CS
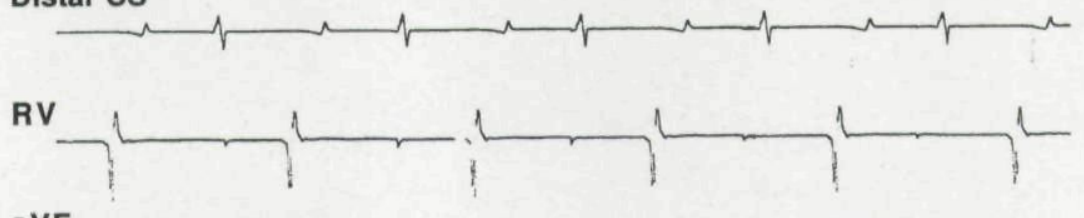

aVF

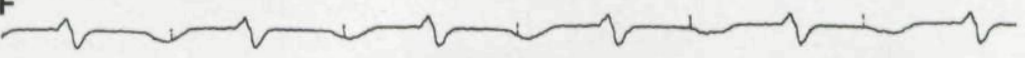

A

$500 \mathrm{msec}$

V1
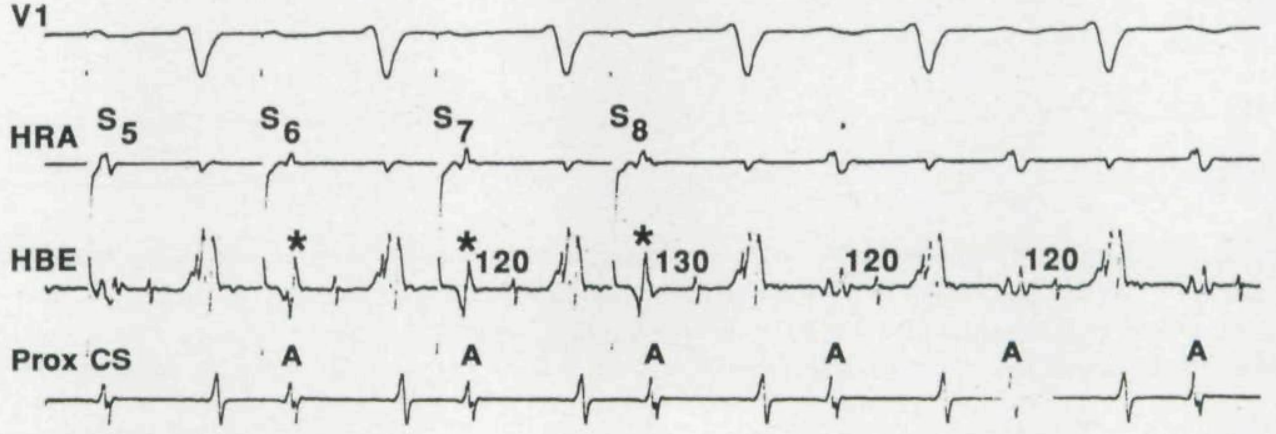

Distal CS

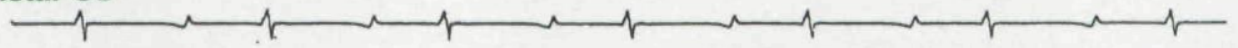

RV

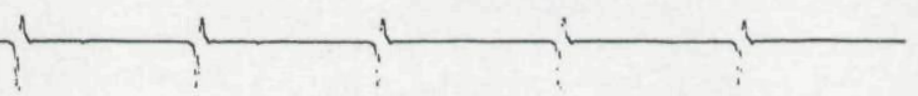

aVF

B

$500 \mathrm{msec}$

Figure 7. Entrainment of atypical AV nodal reentrant tachycardia (AVNRT) by pacing the high right atrium (HRA). (A) Atypical AVNRT at cycle length of $380 \mathrm{msec}$. The onset of atrial pacing at a cycle length of $370 \mathrm{msec}$ is shown. The first five pacing stimuli $(S)$ do not alter the tachycardia. (B) Continuation of panel A. The last three pacing stimuli $\left(S_{\sigma}-S_{8}\right)$ capture the high right atrium and entrain the tachycardia, as evidenced by the change in morphology of the atrial electrogram (asterisks) in the His-bundle electrogram $(H B E)$. The atrial electrogram $(A)$ recorded in the proximal coronary sinus (proximal CS) is unaltered in morphology during entrainment, between the high right atrium and coronary sinus. Note that the longest AH interval during entrainment is $130 \mathrm{msec}$, only $10 \mathrm{msec}$ longer than the AH interval during tachycardia. In contrast, when pacing at a cycle length of $380 \mathrm{msec}$ in the setting of sinus rhythm, the $\triangle A H$ in this patient was $80 \mathrm{msec}$. 


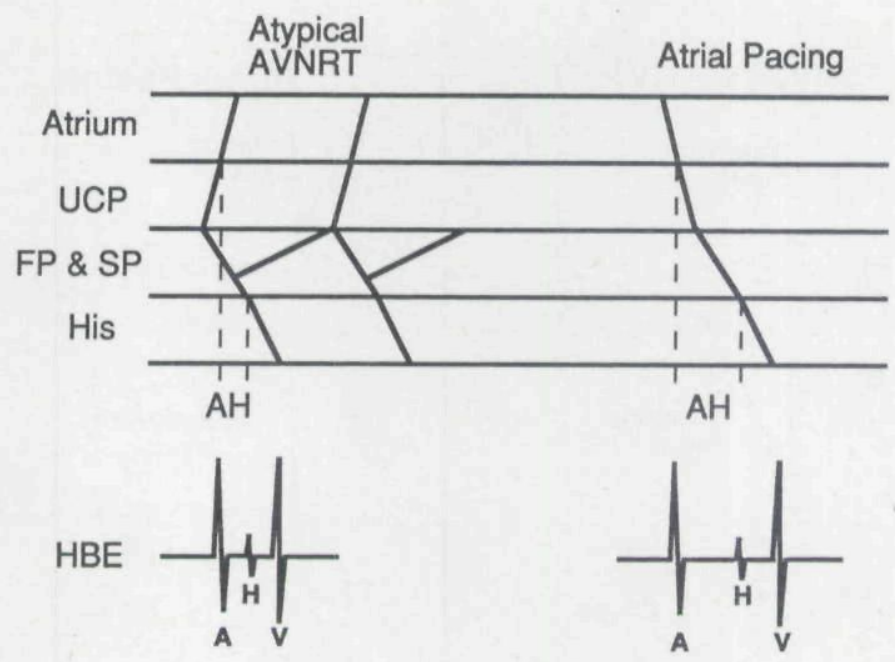

Figure 8. A schematic ladder diagram demonstrating how an upper common pathway (UCP) may be a possible mechanism for the difference in the AH interval between atypical AV nodal reentrant tachycardia (AVNRT) and atrial pacing. During the tachycardia, there is anterograde conduction through the fast pathway $(F P)$ and simultaneous retrograde conduction through the UCP. Therefore, the AH interval during the tachycardia represents the difference between the anterograde conduction time through the fast pathway and lower common pathway and the retrograde conduction time through the UCP. In contrast, during atrial pacing, there is sequential anterograde conduction through the UCP then the fast pathway and lower common pathway. Therefore, the AH interval would be longer than during tachycardia. Assuming that anterograde and retrograde conduction times in the UCP are equal, the $\triangle A H$ would be equal to twice the conduction time through the UCP.AH=atrialHis interval; $H B E=$ His-bundle electrogram; $S P=$ slow pathway.

\section{Atrial Recording Site (Fig. 9)}

It is possible that the site at which the atrial depolarization in the His-bundle electrogram is recorded is not located at the site of input into the AV node during AVNRT. This would result in a different sequence of atrial activation during atrial pacing than during tachycardia and provides another possible explanation for the small $\Delta \mathrm{AH}$ that occurred in some patients with orthodromic reciprocating tachycardia and atrial tachycardia. However, this explanation would not account for why the $\triangle \mathrm{AH}$ in patients with atypical AVNRT is significantly greater than in the other patients.

\section{Limitations}

A limitation of the diagnostic pacing maneuver described in this study is that it cannot be used in patients who have AV block during pacing at the same cycle length as the tachycardia. Approximately $10 \%$ of the patients with a long RP tachycardia were excluded from this study for this reason.

A second limitation is the theoretical possibility that the presence of dual AV nodal physiology in a patient with orthodromic reciprocating tachycardia or atrial tachycardia might result in a long $\Delta \mathrm{AH}$, mimicking the findings expected with atypical
AVNRT. Of note is that approximately $20 \%$ of the patients in this study with either orthodromic reciprocating tachycardia or atrial tachycardia also had dual AV nodal physiology, but in none of these patients was the $\triangle \mathrm{AH}$ longer than $20 \mathrm{msec}$. Nevertheless, the possibility that a $\Delta \mathrm{AH}>40 \mathrm{msec}$ might occur in a patient with orthodromic reciprocating tachycardia or atrial tachycardia who also had dual AV nodal physiology cannot be ruled out.

\section{Conclusions}

In patients who are found to have a long PR tachycardia in the electrophysiology laboratory, it is useful to pace the high right atrium at the same cycle length as the tachycardia in the setting of sinus rhythm and to compare the $\mathrm{AH}$ intervals during tachycardia and during pacing. If the $\mathrm{AH}$ interval during pacing is more than $40 \mathrm{msec}$ longer than during tachycardia, there is a high degree of likelihood that the tachycardia is due to atypical AVNRT. If the AH intervals during pacing and tachycardia differ by less than 10 to $20 \mathrm{msec}$, this does not rule out atypical AVNRT, but is suggestive that the tachycardia is orthodromic reciprocating tachycardia or an atrial tachycardia. This simple diagnostic maneuver may be helpful in facilitating the diagnosis of atypical AVNRT. 

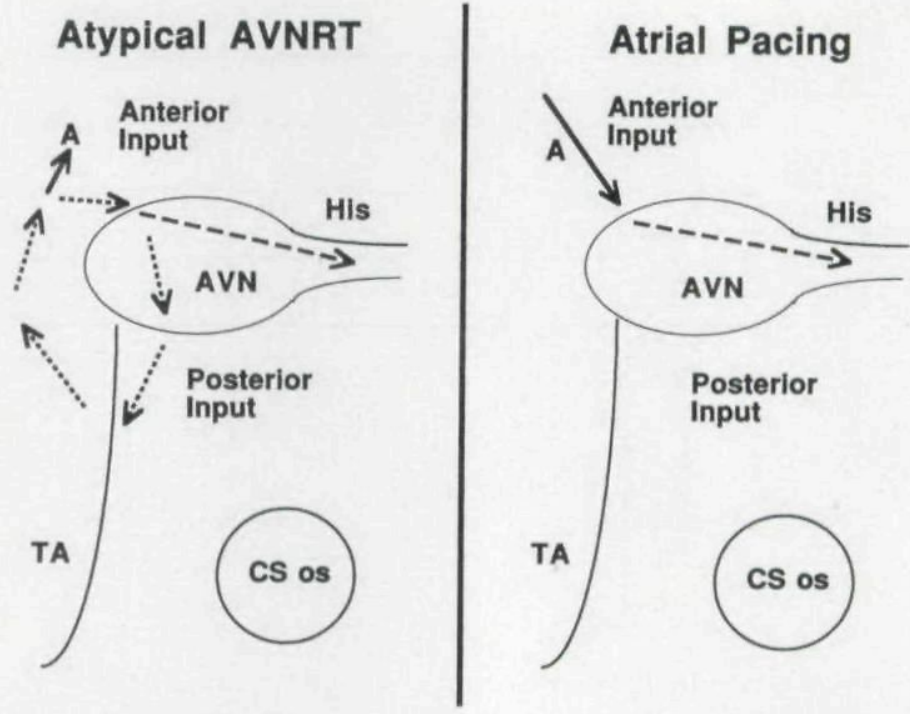

Figure 9. A schematic illustration of how the atrial recording site might account for a different AH interval during tachycardia and pacing. In the left panel is shown a schematic model of atypical AV nodal reentrant tachycardia $(A V N R T)$ utilizing the compact atrioventricular node $(A V N)$ and its anterior and posterior inputs. This model is based on the results of high-resolution intraoperative mapping studies in patients with atypical (fast-slow) AVNRT. ${ }^{12}$ If the atrial recording site (A) is not located at the point of entry of the tachycardia wavefront (dashed arrows) into the AVN, there may be simultaneous conduction of the tachycardia wavefront to "A" (solid arrow) and into the AVN. In contrast, the right panel demonstrates that during high right atrial pacing, there would be sequential activation of "A," then the AVN. Therefore, the AH interval during pacing would be longer than during tachycardia. CS os = coronary sinus ostium; TA = tricuspid annulus.

\section{References}

1. Josephson ME, Wellens HJJ: Differential diagnosis of supraventricular tachycardia. Cardiol Clin 1990;8:411-442.

2. Farré J, Ross D, Wiener I, et al: Reciprocal tachycardia using accessory pathways with long conduction times. Am J Cardiol 1979;44:1099-1109.

3. Leitch J, Klein GJ, Yee R, et al: Invasive electrophysiologic evaluation of patients with supraventricular tachycardia. Cardiol Clin 1990;8:465-477.

4. Kadish AH, Morady F: The response of paroxysmal supraventricular tachycardia to overdrive atrial and ventricular pacing: Can it help determine the tachycardia mechanism? J Cardiovasc Electrophysiol 1993;4:239-252.

5. Ross DL, Uther JB: Diagnosis of concealed accessory pathways in supraventricular tachycardia. PACE 1984;7:1069-1085.

6. Josephson ME: Clinical Cardiac Electrophysiology: Techniques and Interpretations. 2nd Ed. Lea \& Febiger, Malvern, 1993, pp. 181-274.

7 Chien WW, Wang YS, Epstein LM, et al: Ventricular septal summit stimulation in atrioventricular nodal reentrant tachycardia. Am J Cardiol 1993;72:12681273.

8. Paul T, Moak JP, Morris C, et al: Epicardial mapping: How to measure local activation? PACE 1990;13:285292.

9. Miller JM, Rosenthal ME, Vassallo JA, et al: Atrioventricular nodal reentrant tachycardia: Studies on upper and lower "common pathway." Circulation 1987; 75:930-940.

10. Janse MJ, Anderson RH, McGuire MA, et al: "AV nodal" reentry: Part I: "AV nodal" reentry revisited. J Cardiovasc Electrophysiol 1993;4:561-572.

11. McGuire MA, Janse MJ, Ross DL: "AV nodal" reentry: Part II: AV nodal, AV junctional, or atrionodal reentry? J Cardiovasc Electrophysiol 1993;4: 573-586.

12. McGuire MA, Bourke JP, Robotin MC, et al: High resolution mapping of Koch's triangle using sixty electrodes in humans with atrioventricular junctional (AV nodal) reentrant tachycardia. Circulation 1993;88:2315-2328.

13. Satoh M, Miyamima S, Koyama S, et al: Orthodromic capture of the atrial electrogram during transient entrainment of atrioventricular nodal reentrant tachycardia. Circulation 1993;:88:2329-2336.

14. Keim S, Werner P, Jazayeri M, et al: Localization of the fast and slow pathways in atrioventricular nodal reentrant tachycardia by intraoperative ice mapping. Circulation 1992;86:919-925.

15. McGuire MA, Lau KC, Johnson DC, et al: Patients with two types of atrioventricular junctional (AV nodal) reentrant tachycardia. Evidence that a common pathway of nodal tissue is not present above the reentrant circuit. Circulation 1992;86:919-925.

16. Natale A, Klein G, Yee R, et al: Shortening of fast pathway refractoriness after slow pathway ablation. Circulation 1994;89:1103-1108. 
This document is a scanned copy of a printed document. No warranty is given about the accuracy of the copy. Users should refer to the original published version of the material. 